\title{
Ethnicity and long-term course and outcome of psychotic disorders in a UK sample: the $\mathbb{E} E S O P-10$ study
}

Craig Morgan, Paul Fearon, Julia Lappin, Margaret Heslin, Kim Donoghue, Ben Lomas, Ulrich Reininghaus, Adanna Onyejiaka, Tim Croudace, Peter B. Jones, Robin M. Murray, Gillian A. Doody and Paola Dazzan

\section{Background}

The incidence of psychotic disorders is elevated in some minority ethnic populations. However, we know little about the outcome of psychoses in these populations.

\section{Aims}

To investigate patterns and determinants of long-term course and outcome of psychoses by ethnic group following a first episode.

\section{Method}

EESOP-10 is a 10-year follow-up of an ethnically diverse cohort of 532 individuals with first-episode psychosis identified in the UK. Information was collected, at baseline, on clinical presentation and neurodevelopmental and social factors and, at follow-up, on course and outcome.

\section{Results}

There was evidence that, compared with White British, Black
Caribbean patients experienced worse clinical, social and service use outcomes and Black African patients experienced worse social and service use outcomes. There was evidence that baseline social disadvantage contributed to these disparities.

\section{Conclusions}

These findings suggest ethnic disparities in the incidence of psychoses extend, for some groups, to worse outcomes in multiple domains.

\section{Declaration of interest}

None.

\section{Copyright and usage}

(c) The Royal College of Psychiatrists 2017. This is an open access article distributed under the terms of the Creative commons Attribution (CC BY) licence.
The incidence of psychotic disorders is elevated in many, but not all, minority ethnic groups. ${ }^{1-4}$ In addition, those with a psychotic disorder from these groups (for example Black Caribbean, Black African in the UK) experience more negative pathways to and through care ${ }^{5-9}$ These are remarkably consistent findings. By contrast, there has been less research on the course and outcome of psychotic disorders in minority ethnic groups following a first episode. $^{10}$ This means important questions about the development of psychotic disorders in minority ethnic groups remain unanswered. For example, some have suggested that the high incidence in some minority populations is because of misdiagnosis (i.e. misinterpretation of culturally appropriate expressions of distress as symptoms of schizophrenia) or an excess of brief reactive psychoses. ${ }^{11,12}$ If true, then symptomatic course and outcome should be more benign in patients from these groups. There is some support for this. McKenzie et al, ${ }^{13}$ in a UK sample of 113 consecutive admissions followed at 4 years, found that Black Caribbean patients were around $70 \%$ less likely to have a continuous course than White British. However, other studies have reported either no differences or worse clinical outcomes in minority groups; ${ }^{14-18}$ and most suggest poorer social and service use outcomes (for example Birchwood et al ${ }^{17}$ ). Moreover, the methodological quality of these studies is variable and there is considerable heterogeneity in geographical and historical context, design, sample sizes, length of follow-up and outcomes measured. ${ }^{10}$ Consequently, whether there are differences between ethnic groups in course and outcome and whether these vary by group, generation and context - and if so why - is not clear. We established ÆSOP-10 to investigate any differences among ethnic groups in the UK (specifically, White British, Black Caribbean, and Black African) in the course and outcome of psychotic disorders. ${ }^{19}$ We sought to describe course and outcome across three domains (clinical, social and service use) and test the hypotheses that: (a) compared with White British, Black Caribbean and Black African patients have better clinical, but worse social and service use, outcomes; and (b) differences in course and outcome are, at least partly, explained by baseline social, but not clinical, substance use or neurodevelopmental factors.

\section{Method}

ÆSOP-10 is a follow-up at 10 years of a cohort of individuals with a first-episode psychotic disorder initially identified in south-east London and Nottingham, UK. ${ }^{19,20}$ The catchment areas in southeast London (Lambeth, Southwark) and Nottingham are among the most deprived in the UK (i.e. ranked 14, 25 and 17 most deprived of 326 local authorities) and the catchment area in south-east London has high proportions from minority ethnic groups (44.3\%), especially Black Caribbean (8\%) and Black African (14\%). Ethical approval was provided by the Joint South London and Maudsley and Institute of Psychiatry NHS Research Ethics Committee (Ref: 321/02) and the North Nottinghamshire Local Research Ethics Committee (Ref: 04/Q2402/35).

\section{Follow-up procedures}

At baseline, detailed re-contact information was collected for all patients. At approximately 10 years, we sought to re-contact and re-interview each patient, first, via mental health services and, then, if not in contact with services, via their last known address or general practitioner. All deaths and emigrations up to 12 December 2012 were identified through the Office for National 
Statistics for England and Wales and the General Register Office for Scotland.

\section{Baseline data collection}

At baseline, all individuals with a first-episode psychotic disorder who presented to mental health services in our catchment areas over 2 years were identified. Data were collected on clinical presentation, sociodemographic characteristics and a range of neurodevelopmental and social risk factors. ${ }^{21}$ To capture exposure to multiple disadvantages and isolation, we constructed an index by counting the presence of the following: unemployment, living alone, living in rented housing and being single. Baseline diagnoses were determined by consensus, masked to ethnicity, using data collected with the Schedules for Clinical Assessment in Neuropsychiatry (SCAN). ${ }^{22}$ Ethnicity was assigned by researchers at baseline, based on all available information (i.e. principally self-ascription; if not available, then place of birth and parents' places of birth), using 2001 UK Census categories. ${ }^{2}$

\section{Follow-up data collection}

At follow-up, information was collated across three domains (clinical, social, service use) using an extended version of the World Health Organization (WHO) Life Chart ${ }^{23-25}$ and the Global Assessment of Function Disability (GAF-D) scale. ${ }^{26}$ These tools are drawn from a suite of cross-culturally valid and reliable assessments that have been used extensively over many years in cross-cultural studies of psychoses and are the gold standard for research on psychoses globally. ${ }^{23,25,27-30}$ Using all information from follow-up interviews with patients and treating clinicians and from clinical records, researchers painstakingly reconstructed patient histories over the follow-up period.

\section{Clinical}

All Life Chart clinical ratings were determined by consensus, masked to ethnicity. ${ }^{19}$ Following Andreasen et al, ${ }^{31}$ we defined remission as absence of overt psychotic symptoms (based on SCAN rating criteria ${ }^{19,22}$ ) for a period of at least 6 months. We categorised course into three types: episodic (no episode lasting more than 6 months); continuous (no remission lasting more than 6 months); and neither episodic nor continuous (at least one episode of more than 6 months and at least one remission of more than 6 months). ${ }^{25}$ We defined symptom recovery as sustained remission for 2 or more years. ${ }^{32}$

\section{Social}

Information on markers of social disadvantage and isolation across a number of domains during and at follow-up was collected using the Life Chart. The GAF-D scale, ${ }^{26}$ which provides information on overall social function, was completed for the 1 month before the follow-up.

\section{Service use}

Information on contacts with mental health services, including overall adherence with treatment (broadly grouped into regular, irregular and none, based on attendance at appointments and how often medication was taken), throughout the follow-up was collated using the Life Chart.

\section{Analysis}

To test our first hypothesis we fit univariable regression models for each course and outcome variable with ethnicity as the independent variable. We then adjusted estimated effects for study centre, age, gender and baseline diagnosis. To test our second hypothesis, we first identified candidate explanatory variables. These were those baseline variables that were associated with ethnicity and, independently, with one or more course and outcome variable (at $P=0.05$ ). The following did not meet these requirements: baseline symptom severity, parental history of psychosis, neurological soft signs, separation from or death of a parent during childhood, and lifetime substance misuse or dependence. There was some evidence that duration of untreated psychosis, education, and indicators of social disadvantage and isolation were associated both with ethnicity and with one or more outcome(s). We then repeated the first set of analyses and further adjusted for (a) identified baseline factors in those patients with complete data on all included variables and (b) other course variables. All analyses were conducted in Stata v. 13. Analyses were completed on the full sample. For this paper, we focus on findings for White British, Black Caribbean and Black African ethnic groups as the numbers of individuals in other groups were insufficient to allow for meaningful comparisons.

\section{Results}

At follow-up, of the 532 first-episode ÆESOP patients, 37 (7.0\%) had died, $29(5.5 \%)$ had emigrated and $8(1.5 \%)$ were excluded. ${ }^{19}$ For the remaining 458 patients, information on course and outcome in at least one domain was available for $387(84.5 \%)$ for at least 8 years of follow-up (mean 10.7 years, s.d. $=1.2$, range 8.1-13.7; total 4141 years of follow-up) (online Table DS1). ${ }^{19}$ Of these, 320 were of White British $(n=167)$, Black Caribbean $(n=108)$ or Black African ethnicity $(n=45)$.

\section{Clinical}

Contrary to our hypothesis, there was no evidence that Black Caribbean or Black African patients had better clinical outcomes than White British. For Black Caribbean patients (but not Black African), course and outcome were worse (online Table DS2, Table 1 and Fig. 1).

First, the probability of remission over time was lower (or, put differently, time to remission was longer) among Black Caribbean patients, although the evidence for this was weak once study centre, age, gender and baseline diagnosis were adjusted for (adjusted hazard ratio $(\mathrm{HR})=0.75,95 \%$ CI 0.53-1.07; Table 1; online Fig. DS1). Second, Black Caribbean patients were almost three times more likely to experience a continuous course and two times more likely to experience a course that was neither continuous nor episodic (Fig. 1). Overall, Black Caribbean patients were around two times more likely to have a non-episodic course (adjusted odds ratio (OR) $=2.27,95 \%$ CI 1.09-4.76) (Table 1). Third, at follow-up, Black Caribbean patients were around $60 \%$ less likely to have recovered symptomatically $(38.7 \% \mathrm{v}$. $55.5 \%$ in White British; adjusted OR $=0.42$, 95\% CI $0.22-0.80$ ) (Table 1). Furthermore, a greater proportion of Black Caribbean patients experienced negative $(33.7 \%$ v. $23.6 \%$ White British, $\chi^{2}=2.94$, d.f. $\left.=1, P=0.087\right)$ and, when in an episode, severe symptoms $\left(26.0 \%\right.$ v. $11.8 \%$ White British; $\chi^{2}=8.86$, d.f. $=2$, $P=0.012$ ) (Table DS2). There was no clear evidence in our data that these findings varied by generational status, albeit numbers were small when the sample was stratified and statistical power was consequently limited (online Table DS3).

We next repeated analyses and adjusted for further possible confounders in those patients for whom we had complete data on relevant variables (online Table DS4). We found: (a) the association between Black Caribbean ethnicity and time to 


\begin{tabular}{|c|c|c|c|}
\hline & White British & Black Caribbean & Black African \\
\hline \multicolumn{4}{|c|}{ Time to remission, weeks $(n=269)$} \\
\hline Unadjusted HR (95\% Cl) & 1.00 & $0.65^{\star *}(0.48-0.89)$ & $0.79(0.53-1.17)$ \\
\hline Adjusted HR (95\% Cl) & 1.00 & $0.75(0.53-1.07)$ & $0.87(0.56-1.36)$ \\
\hline \multicolumn{4}{|c|}{ Course, non-episodic $v$. episodic $(n=287)$} \\
\hline Unadjusted OR (95\% Cl) & 1.00 & $2.34^{* *}(1.30-4.20)$ & $1.20(0.58-2.48)$ \\
\hline Adjusted OR (95\% Cl) & 1.00 & $2.27 *(1.09-4.76)$ & $1.04(0.42-2.54)$ \\
\hline \multicolumn{4}{|c|}{ Any self-harm $v$. none $(n=264)$} \\
\hline Unadjusted OR (95\% Cl) & 1.00 & $0.45^{*}(0.21-0.94)$ & $0.38(0.13-1.17)$ \\
\hline Adjusted OR $(95 \% \mathrm{Cl})$ & 1.00 & $0.32 * *(0.14-0.76)$ & $0.26 *(0.08-0.88)$ \\
\hline \multicolumn{4}{|c|}{ Any suicide attempt $v$. none $(n=266)$} \\
\hline Unadjusted OR (95\% Cl) & 1.00 & $0.93(0.49-1.78)$ & $0.42(0.14-1.27)$ \\
\hline Adjusted OR $(95 \% \mathrm{Cl})$ & 1.00 & $0.68(0.32-1.43)$ & $0.29 *(0.09-0.96)$ \\
\hline \multicolumn{4}{|c|}{ Recovered (symptoms) $(n=249)$} \\
\hline Unadjusted OR (95\% Cl) & 1.00 & $0.51 *(0.29-0.88)$ & $0.68(0.33-1.43)$ \\
\hline Adjusted OR $(95 \% \mathrm{Cl})$ & 1.00 & $0.42 * *(0.22-0.80)$ & $0.50(0.21-1.19)$ \\
\hline \multicolumn{4}{|c|}{$\begin{array}{l}\text { HR, hazard ratio; OR, odds ratio. } \\
\text { a. } n \text { refers to White British, Black Caribbean and Black African only. Adjusted ratios are adjusted for study centre, age, gender and baseline diagnosis. } \\
{ }^{*} P \leqslant 0.05 ;{ }^{* * P \leqslant 0.01 .}\end{array}$} \\
\hline
\end{tabular}

remission was attenuated (for example, adjusted $\mathrm{HR}=0.88,95 \%$ CI $0.62-1.26 ; n=298$ ); (b) the magnitude of the association between Black Caribbean ethnicity and a non-episodic course remained similar after adjusting for duration of untreated psychosis and education (adjusted OR $=2.03,95 \%$ CI $0.87-4.73 ; n=311$ ), but was attenuated after adjusting additionally for baseline social disadvantage and isolation (adjusted $\mathrm{OR}=1.51,95 \%$ CI $0.62-3.68$; $n=311$ ); and (c) the magnitude of the association between Black Caribbean ethnicity and symptomatic recovery at follow-up remained similar (for example, adjusted $\mathrm{OR}=0.50,95 \% \mathrm{CI}$ $0.25-1.02 ; n=275)$. When we further adjusted for overall adherence to treatment, the magnitude of associations between Black Caribbean ethnicity and both course and recovery at follow-up were largely unchanged (online Table DS5).

Finally, over the follow-up, self-harm was less likely among Black Caribbean (adjusted $\mathrm{OR}=0.32$, 95\% CI 0.14-0.76, $P=0.010$ ) and Black African (adjusted OR $=0.26$, 95\% CI 0.08 $0.88, P=0.030$ ) patients and a suicide attempt was less likely among Black African patients (adjusted OR=0.29, 95\% CI $0.09-0.96, P=0.043$ ) (Table 1). When we repeated analyses and adjusted for further possible confounders, these findings broadly held (online Table DS5).

\section{Social}

In line with our hypothesis, we found that Black Caribbean and, more tentatively, Black African patients experienced worse social outcomes (Table DS2). At baseline, there were marked differences between White British and both Black Caribbean and Black African patients in the extent of social disadvantage and isolation. ${ }^{33}$ Using unemployment as an indicator, these differences largely persisted over the follow-up. Against a background of high levels of unemployment for all patients, Black Caribbean patients were around five times and Black African around three times more likely than White British to be employed for less than $75 \%$ of the follow-up (Table 2). These differences mirror those in the local populations from which patients were identified (for example, in 2011 in south London, 63\% White British in paid employment v. $47 \%$ Black Caribbean and $53 \%$ Black African ${ }^{34}$ ). Emphasising the extent to which these patterns are set early and persist, only 1 (of 21; 5\%) Black African patient, 3 (of 54; 6\%) Black Caribbean patients, and 9 (of 63;14\%) White British patients who were unemployed at baseline were employed at follow-up. The data for relationship status were less clear, but still broadly suggestive of greater isolation (i.e. more often single) in Black Caribbean and Black African patients, especially at follow-up (Table 2).

More broadly, there was evidence of global differences in social function between White British and both Black Caribbean and Black African patients. Mean GAF-D scores were lower for both Black Caribbean $(49.7$, s.d. $=16.6)$ and, to a lesser extent, Black African patients $(55.1$, s.d. $=19.3)$ compared with White British $(61.3$, s.d. $=17.8)($ Table DS2 and Table 2$)$.

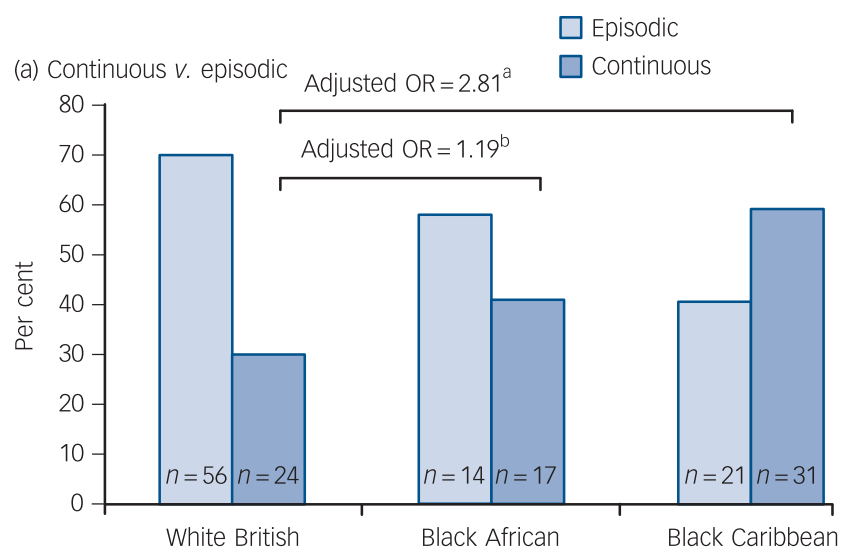

(b) Neither $v$. episodic Adjusted $\mathrm{OR}=2.01^{\mathrm{C}}$

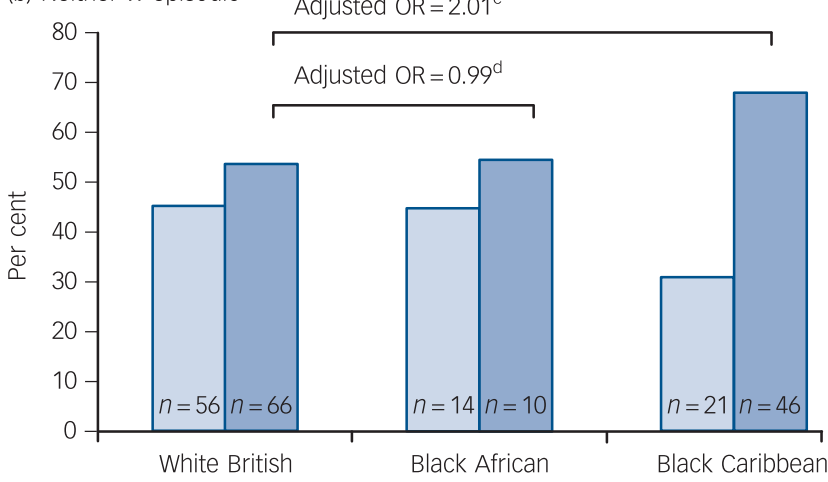

Fig. 1 Course type by ethnic group.

Odds ratios adjusted for study centre, age, gender and baseline diagnosis. a. $95 \% \mathrm{Cl}$ $1.15-6.92, P=0.024 ;$ b. $95 \% \mathrm{Cl} 0.39-3.68, P=0.760 ; \mathrm{C} .95 \% \mathrm{Cl} 0.92-4.36, P=0.079$; d. $95 \% \mathrm{Cl} 0.38-2.57, P=0.980$. 


\begin{tabular}{|c|c|c|c|}
\hline & White British & Black Caribbean & Black African \\
\hline \multicolumn{4}{|l|}{$\%$ time employed (<75\%) $(n=238)$} \\
\hline Unadjusted OR (95\% Cl) & 1.00 & $7.01 * *(2.03$ to 24.27$)$ & $3.71(0.82$ to 16.67$)$ \\
\hline Adjusted OR $(95 \% \mathrm{Cl})$ & 1.00 & $5.19 *(1.32$ to 20.32$)$ & $3.03(0.57$ to 15.97$)$ \\
\hline \multicolumn{4}{|l|}{ Employed at follow-up $(n=246)$} \\
\hline Unadjusted OR (95\% Cl) & 1.00 & $0.40 * *(0.19$ to 0.81$)$ & $0.43(0.15$ to 1.19$)$ \\
\hline Adjusted OR $(95 \% \mathrm{Cl})$ & 1.00 & $0.43(0.18$ to 1.03$)$ & $0.43(0.13$ to 1.41$)$ \\
\hline \multicolumn{4}{|c|}{ Main during follow-up, not in relationship $(n=255)$} \\
\hline Unadjusted OR (95\% Cl) & 1.00 & $2.10 *(1.15$ to 3.81$)$ & $3.91 * *(1.42$ to 10.77$)$ \\
\hline Adjusted OR $(95 \% \mathrm{Cl})$ & 1.00 & $1.65(0.81$ to 3.34$)$ & $3.31 *(1.09$ to 10.11$)$ \\
\hline \multicolumn{4}{|l|}{ At follow-up, not in relationship $(n=251)$} \\
\hline Unadjusted OR $(95 \% \mathrm{Cl})$ & 1.00 & $2.22^{\star *}(1.21$ to 4.08$)$ & $1.69(0.75$ to 3.81$)$ \\
\hline Adjusted OR (95\% Cl) & 1.00 & $1.68(0.83$ to 3.43$)$ & $1.32(0.52$ to 3.34$)$ \\
\hline \multicolumn{4}{|l|}{ GAF disability score $(n=234)$} \\
\hline Unstandardised unadjusted $\beta$ (95\% Cl) & Reference $^{b}$ & $-11.64 * *(-16.60$ to -6.69$)$ & $-6.21(-13.13$ to 0.72$)$ \\
\hline Unstandardised adjusted $\beta(95 \% \mathrm{Cl})$ & Reference $^{c}$ & $-7.85^{\star *}(-13.06$ to -2.63$)$ & $-4.25(-11.35$ to 2.84$)$ \\
\hline \multicolumn{4}{|c|}{$\begin{array}{l}\text { GAF, Global Assessment of Function. } \\
\text { a. } n \text { refers to White British, Black Caribbean and Black African only. Adjusted figures are adjusted for study centre, age, gender and baseline diagnosis. } \\
\text { b. Constant: } 61.30 \text {. } \\
\text { c. Constant: } 54.28 \text {. } \\
{ }^{\star} P \leqslant 0.05 ;{ }^{*} P \leqslant 0.01 \text {. }\end{array}$} \\
\hline
\end{tabular}

When we again repeated analyses and adjusted for further possible confounders, including for clinical course (online Tables DS6 and DS7), the findings on employment and social function for Black Caribbean patients held. For example, after adjusting for clinical course, Black Caribbean patients were still over four times more likely than White British to be employed for less than $75 \%$ of the follow-up (for example, adjusted OR $=4.30,95 \% \mathrm{CI}$ 1.09-17.02, $n=284$ ) and still had markedly lower mean GAF-D scores at follow-up (adjusted $\beta=-5.49,95 \%$ CI -10.56 to $-0.42, n=277$ ). The findings for Black African patients were less robust (Tables DS6 and DS7).

\section{Service use}

In line with our hypothesis, we found that, during the follow-up, hospital admissions were more frequent, longer and more often involved the police and compulsion in Black Caribbean and Black African patients than White British (Table DS2). The numbers and rates of admissions were greater in Black Caribbean and Black African patients than in White British. For example, patients in both groups were admitted at a rate of around 0.36 per year (or once every 3 years) compared with a rate of 0.26 per year (or once every 4 years) for White British patients. After taking account of study centre, age, gender and baseline diagnosis, Black Caribbean and Black African patients were admitted at a rate that was around 20\% higher than White British patients (Table 3). Further, admissions tended to be longer. Compared with a median length of 37 days for White British patients, the median in-patient stay for Black Caribbean was 62 days (rank sum test $z=-3.53$, $P<0.001$ ) and for Black African it was 54 days (rank sum test $z=-2.12, P=0.034$ ) (Table DS2).

The most striking differences were in police involvement and in compulsory admissions. First, rates of admissions involving the police were around two times higher in Black Caribbean and Black African patients compared with White British; overall, over $60 \%$ of Black Caribbean and Black African patients had police involvement in at least one admission compared with $37 \%$ of White British (Table DS2 and Table 3). Second, rates of compulsory admissions were almost two times higher in both Black Caribbean and Black African patients compared with White British; overall, $79 \%$ of Black Caribbean and $84 \%$ of Black African patients were admitted compulsorily at some point compared

\begin{tabular}{|c|c|c|c|}
\hline & White British & Black Caribbean & Black African \\
\hline \multicolumn{4}{|c|}{ Admissions, rate ratios $(n=281)$} \\
\hline Unadjusted IRR (95\% Cl) & 1.00 & $1.41^{* *}(1.23-1.63)$ & $1.38 * *(1.14-1.63)$ \\
\hline Adjusted IRR (95\% CI) & 1.00 & $1.22^{* *}(1.04-1.44)$ & $1.18(0.96-1.45)$ \\
\hline \multicolumn{4}{|c|}{ Compulsory admissions, rate ratios $(n=272)$} \\
\hline Unadjusted IRR (95\% Cl) & 1.00 & $2.21 * *(1.83-2.68)$ & $2.22 * *(1.75-2.82)$ \\
\hline Adjusted IRR (95\% Cl) & 1.00 & $1.85^{\star *}(1.48-2.31)$ & $1.84^{\star *}(1.40-2.42)$ \\
\hline \multicolumn{4}{|c|}{ Compulsory admission, ever $(n=303)$} \\
\hline Unadjusted OR (95\% Cl) & 1.00 & $2.62^{* *}(1.50-4.61)$ & $3.70 * *(1.55-8.84)$ \\
\hline Adjusted OR $(95 \% \mathrm{Cl})$ & 1.00 & $2.45^{* *}(1.26-4.74)$ & $3.58 * *(1.35-9.48)$ \\
\hline \multicolumn{4}{|c|}{ Police involvement, rate ratios $(n=271)$} \\
\hline Unadjusted IRR (95\% Cl) & 1.00 & $3.32 * *(2.52-4.36)$ & $2.52^{\star *}(1.77-3.58)$ \\
\hline Adjusted IRR (95\% Cl) & 1.00 & $2.64^{* *}(1.93-3.61)$ & $1.92 * *(1.30-2.84)$ \\
\hline \multicolumn{4}{|c|}{ Police involvement, ever $(n=309)$} \\
\hline Unadjusted OR (95\% Cl) & 1.00 & $2.87^{* *}(1.73-4.78)$ & $3.05^{\star *}(1.52-6.10)$ \\
\hline Adjusted OR (95\% Cl) & 1.00 & $2.30 * *(1.25-4.24)$ & $2.28 *(1.02-5.13)$ \\
\hline \multicolumn{4}{|c|}{$\begin{array}{l}\text { IRR, incidence rate ratio. } \\
\text { a. } n \text { refers to White British, Black Caribbean and Black African only. Adjusted figures are adjusted for study centre, age, gender and baseline diagnosis. } \\
{ }^{*} P \leqslant 0.05 ;{ }^{*} P \leqslant 0.01 \text {. }\end{array}$} \\
\hline
\end{tabular}


with $58 \%$ of White British patients (Table DS2 and Table 3). Over the follow-up, 69\% (268 of 389) of all admissions of Black Caribbean and $71 \%$ (110 of 155) of Black African patients were compulsory compared with 43\% (169 of 394) of White British.

We once again repeated analyses and adjusted for further possible confounders, this time extending the analyses to adjust for clinical course, employment during the follow-up and for baseline compulsory admission (online Tables DS8 and DS9). When we adjusted for further baseline confounders, differences in rates of admissions between White British and both Black Caribbean and Black African patients were attenuated; however, differences in rates of police involvement and compulsory admissions held, with rate ratios of around two for Black Caribbean and Black African patients (Table DS8). When we next adjusted for clinical course, employment during the follow-up and baseline compulsory admission, differences in the rates of police involvement and compulsory admission between White British and both Black Caribbean and Black African patients were reduced, especially rate ratios for compulsory admission, but still evident (police involvement: Black Caribbean: adjusted incidence rate ratio $(\mathrm{IRR})=1.96,95 \% \mathrm{CI} 1.38-2.77$; Black African: adjusted IRR $=1.83,95 \%$ CI $1.20-2.80(n=272)$; compulsory admissions: Black Caribbean: adjusted IRR $=1.26,95 \%$ CI 0.99-1.61; Black African: adjusted IRR $=1.55,95 \%$ CI $1.15-2.08, n=273$ ) (Table DS9).

\section{Discussion}

ÆSOP-10 provides unique data on ethnic variations in the longterm course and outcome of psychotic disorders. Our findings suggest that the trajectory of psychotic disorders is more often characterised, for Black Caribbean patients, by continuous symptoms and low rates of recovery and, for both Black Caribbean and Black African patients, by reduced likelihood of self-harm and near ubiquitous and persistent social disadvantage and isolation and high rates of admissions involving the police and compulsion. These associations were broadly similar for first and subsequent generation patients, a finding in line with the only other reference we could find in the literature to analyses by generation. $^{13}$

\section{Methodological issues}

There were some differences in attrition between ethnic groups; this may have biased findings if those lost to follow-up (for example because of migration out of the study areas) were higher functioning, with better outcomes. For example, more Black African patients moved abroad. If this group comprised individuals who experienced better outcomes then it may be that the worse outcomes in some domains for Black African patients are overstated. Further, we had no data on 8 or more years of follow-up for more White British patients (38 of 167; 23\%) than for other ethnic groups (for example Black Caribbean: 16 of 108; $15 \%) .{ }^{19}$ It is possible that those White British patients lost to follow-up had poorer outcomes. However, as we were more successful in tracing patients in contact with services, it seems more plausible that those lost to follow-up had, on average, better outcomes. Further, although this is the largest study to date of ethnicity and the course and outcome of first-episode psychosis, the numbers in analyses were still sometimes relatively small. This urges further caution in interpreting our findings, particularly where we observed no clear differences between groups.

Life Chart and clinical ratings were made by consensus, masked to ethnicity, after extensive consideration of all available material. Nonetheless, the completeness and quality of information for each patient inevitably varied and this may have introduced bias. However, there were no discernible patterns in missing data by ethnic group ${ }^{19}$ and, by making clinical ratings masked to ethnicity, we sought to minimise the potential for stereotyping to bias the rating of symptoms in minority ethnic groups.

Further, we were constrained, in analysing explanations for observed ethnic differences, to consider only those variables that we had data on. This means that some possible explanations for variations in outcomes (such as differences in insight, type and nature of clinical interventions received) could not be examined. For others, such as substance use and adherence, our data were crude and it is possible that we underestimated the extent to which these factors contribute to the observed differences in outcomes. Finally, there is a need for caution in extrapolating from our findings to other contexts and other minority ethnic groups.

\section{Clinical course and outcome}

Our finding of worse clinical outcomes for Black Caribbean patients goes against our original hypothesis and much previous speculation. Two previous studies did find better clinical outcomes. ${ }^{3,35}$ Both, however, involved shorter follow-up periods (2, 4 years) and neither were of first-episode samples. Moreover, most other studies have reported either no ethnic differences or worse outcomes for Black and other minority groups. ${ }^{10,14}$ In our sample, the findings are clear: long-term clinical course and outcome were not more benign; for Black Caribbean patients, they were worse. These findings suggest the high incidence of psychoses in these populations is not because of an excess of acute, good prognosis disorders and, by extension, is unlikely to be because of misdiagnosis. (We also found no evidence of ethnic differences in diagnostic stability over time. ${ }^{36}$ ) It is perhaps surprising, given these findings, that self-harm and, to a lesser degree, one or more suicide attempt was less likely among Black Caribbean and Black African patients. The only two other studies we are aware of that have examined these aspects of outcome report similar findings. However, the reasons for this are unclear and more research is evidently needed. Understanding what lies behind these findings may be of benefit for the prevention of self-harm and suicide more generally among those with a psychotic disorder.

There are further nuances to these findings. It is intriguing, for example, that the association between Black Caribbean ethnicity and each course variable appears to get stronger over time (i.e. weakest association is with time to first remission; strongest is with recovery at follow-up). Tentatively, it may be that differences in clinical course develop, widen and become entrenched over time. This may also explain why some studies with short follow-up periods did not find clear differences. Further, the absence of similarly strong evidence of poor clinical outcomes in Black African patients may be because of the small sample size; but it also cautions against inferring that the worse clinical course and outcome in Black Caribbean patients will generalise to other minority groups.

We were able to take the next step and examine candidate explanations for observed ethnic differences. We found no strong evidence that contextual (i.e. study centre), demographic, clinical, substance use or neurodevelopmental factors could account fully for the greater likelihood of a continuous course or the lower rate of symptomatic recovery in the Black Caribbean group. By contrast, there was some - albeit tentative - evidence that baseline social disadvantage and isolation partly accounted for the greater likelihood of a continuous course, but not a lower rate of symptomatic recovery. This raises the possibility that similar social 
factors contribute both to increased rates of disorder and, partly, to persistence of symptoms over time. ${ }^{18}$

\section{Social disadvantage, isolation and function}

Our finding of worse social outcomes for Black Caribbean and Black African patients is consistent with scattered reports from other studies. For example, Birchwood et $a l^{17}$ found, in a first admission sample, that at 1-year follow-up $91 \%$ of Black Caribbean patients were unemployed compared with $70 \%$ of White British. Others have found similar disparities, albeit largely in non-first-episode cohorts. ${ }^{18,37,38}$

Further, ethnic differences in social outcomes were largely independent of baseline factors. There was some evidence that adjusting for clinical course attenuated associations with lower social function at follow-up, but not percentage of time employed. This suggests that ethnic differences in employment were because of additional factors unrelated to clinical course, such as because of wider factors that underpin high rates of unemployment in general in Black Caribbean and Black African populations in the UK. The result is near ubiquitous and long-term disadvantage and isolation for patients from these groups. Moreover, given the tentative finding that baseline social disadvantage may partly explain poor clinical outcomes, it is possible that disadvantage and psychosis are mutually reinforcing, such that disadvantage exacerbates symptoms (and vice versa) in a vicious cycle, the end-point of which, for many Black Caribbean and Black African patients, is entrenched psychosis and enduring social exclusion.

\section{Service use}

High rates of police involvement and compulsory admissions for Black Caribbean and Black African patients have been reported in numerous studies. ${ }^{5,9}$ Our findings extend this literature in three respects. First, they emphasise the extent to which, over time, admissions for patients from these groups involve the police and compulsion. Second, we were able to examine whether baseline and other course variables could account for observed disparities between ethnic groups. No baseline clinical or social variables noticeably affected observed differences. However, the magnitudes of associations were reduced after adjusting for clinical and social course variables and for baseline compulsory admission. This suggests initial experiences of services and both subsequent clinical and social factors may partly account for the high rates of police involvement and compulsory admissions. Finally, our findings emphasise how little has changed over the past 40 years; Black Caribbean and Black African patients continue to be admitted compulsorily at alarmingly high rates in the UK.

\section{Broader context and implications}

More research is needed to clarify what factors drive poor outcomes in Black Caribbean and Black African patients in the UK - and indeed differences in outcome between them - and whether these extend to other groups in other countries. Some tentative proposals that may address these disparities, however, can already be extrapolated from our findings. For example, one of our most striking findings is the high levels of social disadvantage and isolation, at baseline and throughout the follow-up, among Black Caribbean and Black African patients. This suggests that addressing the social needs of those from these groups should be a priority for mental health services. If our tentative findings are right, this may lead to improved clinical outcomes and engagement with services. In the UK, most community mental health services, and early intervention services in particular, do assess and seek to address social needs. However, these tasks often fall on already stretched community mental health staff who may lack specialist knowledge. What this points to is the potential value, alongside clinical care, of enhanced packages of social interventions, particularly for patients from Black and minority ethnic groups. This may be better achieved, moreover, through increasing integration between health and social services. At present, this remains speculative and, in pursuing this line of enquiry, it remains important to explore the possibility that other, currently unknown, factors may drive both enduring disadvantage and poor outcomes.

More broadly, our findings mirror wider inequities in health in many marginalised and disadvantaged groups. This perspective draws attention to the social structures and processes, including institutional racism, that shape access to material resources and health and social services and, through this, contribute to health outcomes. Our findings on the impact of persistent social disadvantage and use of compulsion in Black Caribbean and Black African patients hint at the operation of these processes and, as such, point to the necessity of action at all levels - health systems, public health, social policy - to challenge and reduce these disparities.

\begin{abstract}
Craig Morgan, PhD, Institute of Psychiatry, Psychology \& Neuroscience, King's College London and National Institute for Health Research (NIHR) Biomedical Research Centre at South London and Maudsley NHS Foundation Trust and King's College London, London, UK; Paul Fearon, MRCPsych, Department of Psychiatry, Trinity College Dublin, Dublin, Ireland; Julia Lappin, MRCPsych, School of Psychiatry, University of New South Wales, Randwick, New South Wales, Australia; Margaret Heslin, MSc, Kim Donoghue, PhD, Institute of Psychiatry, Psychology \&

Neuroscience, King's College London, London, UK; Ben Lomas, MRCPsych, Division of Psychiatry, University of Nottingham, Nottingham, UK; Ulrich Reininghaus, PhD, Institute of Psychiatry, Psychology \& Neuroscience, King's College London, London, UK and School of Mental Health and Neuroscience, Maastricht University, The Netherlands; Adanna Onyejiaka, Institute of Psychiatry, Psychology \& Neuroscience, King's College London, UK; Tim Croudace, PhD, School of Nursing and Midwifery, University of Dundee, UK; Peter B. Jones, FRCPsych, Department of Psychiatry, University of Cambridge, Cambridge, UK; Robin M. Murray, FRS, Institute of Psychiatry, Psychology \& Neuroscience, King's College London and National Institute for Health Research (NIHR) Biomedical Research Centre at South London and Maudsley NHS Foundation Trust and King's College London, London, UK; Gillian A. Doody, MRCPsych, Division of Psychiatry, University of Nottingham, Nottingham, UK; Paola Dazzan, MRCPsych, Institute of Psychiatry, Psychology \& Neuroscience, King's College London and National Institute for Health Research (NIHR) Biomedical Research Centre at South London and Maudsley NHS Foundation Trust and King's College London, London, UK
\end{abstract}

Correspondence: Craig Morgan, Society and Mental Health Research Group, Institute of Psychiatry, Psychology \& Neuroscience, King's College London, London SE5 8AF, UK. Email: craig.morgan@kcl.ac.uk

First received 13 Sep 2016, final revision 3 Apr 2017, accepted 6 Apr 2017

\section{Funding}

This work was supported by UK Medical Research Council (Ref: G0500817) and the Department of Health via the National Institute for Health Research (NIHR) Biomedical Research Centre at South London and Maudsley NHS Foundation Trust (SLaM) and King's College London. The views expressed are those of the author(s) and not necessarily those of the NHS, the NIHR or the Department of Health.

\section{References}

1 Cantor-Graae E, Selten JP. Schizophrenia and migration: a meta-analysis and review. Am J Psychiatry 2005; 162: 12-24.

2 Fearon P, Kirkbride JB, Morgan C, Dazzan P, Morgan K, Lloyd T, et al. Incidence of schizophrenia and other psychoses in ethnic minority groups: results from the MRC AESOP Study. Psychol Med 2006; 36: 1541-50.

3 Kirkbride JB, Barker D, Cowden F, Stamps R, Yang M, Jones PB, et al. Psychoses, ethnicity and socio-economic status. Br J Psychiatry 2008; 193: 18-24.

4 Tortelli A, Errazuriz A, Croudace T, Morgan C, Murray RM, Jones PB, et al. Schizophrenia and other psychotic disorders in Caribbean-born migrants and their descendants in England: systematic review and meta-analysis of incidence rates, 1950-2013. Soc Psychiatry Psychiatr Epidemiol 2015; 50: 1039-55. 
5 Bhui K, Stansfeld S, Hull S, Priebe S, Mole F, Feder G. Ethnic variations in pathways to and use of specialist mental health services in the UK. Systematic review. Br J Psychiatry 2003; 182: 105-16.

6 Morgan $\mathrm{C}$, Mallett $\mathrm{R}$, Hutchinson G, Bagalkote $\mathrm{H}$, Morgan $\mathrm{K}$, Fearon $\mathrm{P}$, et al. Pathways to care and ethnicity. 1: sample characteristics and compulsory admission. Report from the AESOP study. Br J Psychiatry 2005; 186: 281-9.

7 Morgan C, Mallett R, Hutchinson G, Bagalkote H, Morgan K, Fearon P, et al Pathways to care and ethnicity. 2: source of referral and help-seeking. Report from the AESOP study. Br J Psychiatry 2005; 186: 290-6.

8 Mulder CL, Koopmans GT, Selten JP. Emergency psychiatry, compulsory admissions and clinical presentation among immigrants to the Netherlands. Br J Psychiatry 2006; 188: 386-91

9 Morgan C, Mallett R, Hutchinson G, Leff J. Negative pathways to psychiatric care and ethnicity: the bridge between social science and psychiatry. Soc SCi Med 2004; 58: 739-52.

10 Chorlton E, McKenzie K, Morgan C, Doody G. Course and outcome of psychosis in Black Caribbean populations and other ethnic groups living in the UK: a systematic review. Int J Soc Psychiatry 2012; 58: 400-8.

11 Fernando S. Mental Health, Race and Culture. Macmillan, 1991.

12 Littlewood R, Lipsedge M. Aliens and Alienists: Ethnic Minorities and Psychiatry (3rd edn). Routledge, 1997.

13 McKenzie K, van Os J, Fahy $T$, Jones P, Harvey I, Toone B, et al. Psychosis with good prognosis in Afro-Caribbean people now living in the United Kingdom. BMJ 1995; 18; 311: 1325-8.

14 Selten J-P, Veen ND, Hoek HW, Laan W, Schols D, van der Tweel I, et al. Early course of schizophrenia in a representative Dutch incidence cohort. Schizophr Res 2007; 97: 79-87.

15 Harrison G, Amin S, Singh SP, Croudace T, Jones P. Outcome of psychosis in people of African-Caribbean family origin. Population-based first-episode study. Br J Psychiatry 1999; 175: 43-9.

16 Goater N, King M, Cole E, Leavey G, Johnson-Sabine E, Blizard R, et al. Ethnicity and outcome of psychosis. Br J Psychiatry 1999; 175: 34-42.

17 Birchwood M, Cochrane R, Macmillan F, Copestake S, Kucharska J, Carriss $M$. The influence of ethnicity and family structure on relapse in first-episode schizophrenia. A comparison of Asian, Afro-Caribbean, and white patients. Br J Psychiatry 1992; 161: 783-90.

18 McGovern $D$, Hemmings $P$, Cope $R$, Lowerson A. Long-term follow-up of young Afro-Caribbean Britons and white Britons with a first admission diagnosis of schizophrenia. Soc Psychiatry Psychiatr Epidemiol 1994; 29: 8-19.

19 Morgan C, Lappin J, Heslin M, Donoghue K, Lomas B, Reininghaus U, et al. Reappraising the long-term course and outcome of psychotic disorders: the AESOP-10 study. Psychol Med 2014; 44: 2713-26.

20 Kirkbride JB, Fearon P, Morgan C, Dazzan P, Morgan K, Tarrant J, et al. Heterogeneity in incidence rates of schizophrenia and other psychotic syndromes: findings from the 3-center AeSOP study. Arch Gen Psychiatry 2006; 63: 250-8.

21 Morgan C, Dazzan P, Morgan K, Jones P, Harrison G, Leff J, et al. First episode psychosis and ethnicity: initial findings from the AESOP study. World Psychiatry 2006; 5: 40-6.

22 World Health Organization. Schedules for Clinical Assessment in Neuropsychiatry. WHO, 1992.
23 Sartorius N, Gulbinat W, Harrison G, Laska E, Siegel C. Long-term follow-up of schizophrenia in 16 countries. A description of the International Study of Schizophrenia conducted by the World Health Organization. Soc Psychiatry Psychiatr Epidemiol 1996; 31: 249-58.

24 Burns T, Creed F, Fahy T, Thompson S, Tyrer P, White I. Intensive versus standard case management for severe psychotic illness: a randomised trial. UK 700 Group. Lancet 1999; 26: 2185-9.

25 Harrison G, Hopper K, Craig T, Laska E, Siegel C, Wanderling J, et al. Recovery from psychotic illness: a 15- and 25-year international follow-up study. Br J Psychiatry 2001; 178: 506-17.

26 Endicott J, Spitzer RL, Fleiss JL, Cohen J. The Global Assessment Scale. A procedure for measuring overall severity of psychiatric disturbance. Arch Gen Psychiatry 1976; 33: 766-71.

27 Susser E, Finnerty M, Mojtabai R, Yale S, Conover S, Goetz R, et al. Reliability of the Life Chart Schedule for assessing the long-term course of schizophrenia. Schizophr Res 2000; 42; 67-77.

28 Jablensky A, Sartorius N, Ernberg G, Anker M, Korten A, Cooper JE, et al (1992) Schizophrenia: manifestations, incidence and course in different cultures. A World Health Organizsation ten-country study. Psychol Med Monogr Suppl 1992; 20: 1-97.

29 Hopper K, Harrison G, Janca A, Sartorius N. Recovery from Schizophrenia: An International Perspective. Oxford University Press, 2007.

30 Sartorius $\mathrm{N}$, Janca A. Psychiatric assessment instruments developed by the World Health Organization. Soc Psychiatry Psychiatr Epidemiol 1996; 31: 55-69.

31 Andreasen NC, Carpenter WT Jr, Kane JM, Lasser RA, Marder SR, Weinberger DR. Remission in schizophrenia: proposed criteria and rationale for consensus. Am J Psychiatry 2005; 162: 441-9.

32 Robinson DG, Woerner MG, MCMeniman M, Mendelowitz A, Bilder RM Symptomatic and functional recovery from a first episode of schizophrenia or schizoaffective disorder. Am J Psychiatry 2004; 161: 473-9.

33 Morgan C, Kirkbride J, Hutchinson G, Craig T, Morgan K, Dazzan P, et al. Cumulative social disadvantage, ethnicity and first-episode psychosis: a casecontrol study. Psychol Med 2008; 38: 1701-15.

34 Office for National Statistics. Official Labour Market Statistics: Economic Activity by Ethnic Group by Sex by Age. ONS, 2011 (http:// www.nomisweb.co.uk/census/2011/dc6201ew).

35 McKenzie K, Samele C, Van Horn E, Tattan T, Van Os J, Murray R. Comparison of the outcome and treatment of psychosis in people of Caribbean origin living in the UK and British Whites. Report from the UK700 trial. Br J Psychiatry 2001; 178: 160-5.

36 Heslin M, Lomas B, Lappin JM, Donoghue K, Reininghaus U, Onyejiaka A, et al. Diagnostic change 10 years after a first episode of psychosis. Psychol Med 2015; 4: 1-13

37 Agius M, Shah S, Ramkisson R, Persaud A, Murphy S, Zaman R. Three year outcomes in an early intervention service for psychosis in a multicultural and multiethnic population. Psychiatr Danub 2008; 20: 494-9.

38 Eack SM, Newhill CE. Racial disparities in mental health outcomes after psychiatric hospital discharge among individuals with severe mental illness. Soc Work Res 2012; 36: 41-52.

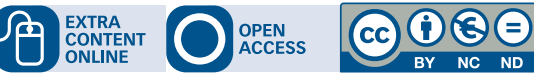

